\title{
La versión facsimilar de la revista Sociedad y Política
}

\section{The facsimile version of the magazine Sociedad y Política}

\author{
César Germaná Cavero \\ Universidad Nacional Mayor de San Marcos \\ cagermana@yahoo.com
}

Sociedad y Política. Edición facsimilar

Fondo Editorial / Facultad de Ciencias Sociales,

Universidad Nacional Mayor de San Marcos, 2019, 812 páginas.

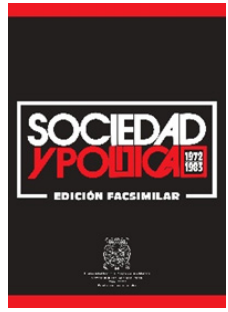

Ha sido un valioso acierto la publicación de la versión facsimilar de los trece números de la revista Sociedad y Política (1972-1983) gracias a la apreciable decisión del Dr. Julio Mejía -decano de la Facultad de Ciencias Sociales- y al excelente trabajo editorial realizado por el director y su equipo del Fondo Editorial de la Universidad Nacional Mayor de San Marcos.

En la coyuntura marcada por el reformismo del régimen militar de Velasco Alvarado, Sociedad y Política surgió como una revista que tenía un claro propósito: "la declarada ambición de contribuir a la profundización y desarrollo del pensamiento y la práctica de la revolución socialista en el Perú" (Editorial del $N^{\circ} 1$ ). Su programa consistía en desarrollar una crítica radical del sistema capitalista así como de las experiencias del socialismo burocrático. Este programa implicaba ir más allá de la simple denuncia de los efectos de la explotación y dominación capitalista "para avanzar hacia una crítica de la estructura y movimiento de este sistema, de sus alternativas y procesos reales de cambio" (Editorial del $N^{\circ} 1$ ). Desde esta perspectiva, en ese momento particular se planteaba la tarea de comprender el significado del reformismo militar teniendo en cuenta lo que estaba ocurriendo en América Latina dentro de un convulso mundo caracterizado por los inicios de una crisis estructural.

Sociedad y Política no representaba a un grupo o partido. Encarnaba, más bien, una corriente, en el campo intelectual y político, que buscaba continuar con la tarea que se había propuesto el Amauta José Carlos Mariátegui: "crear un Perú nuevo dentro del mundo nuevo".

Los responsables de la edición de la revista -bajo la dirección de Aníbal Quijanofueron distinguidos intelectuales que asumían la necesaria tarea de trabajar por una ciencia social comprometida con la búsqueda de un orden social más justo, 
más democrático y más igualitario. Los artículos publicados en Sociedad y Política muestran de manera bastante evidente esta perspectiva del conocimiento crítico. Son reflexiones, a la vez, intelectualmente rigurosas, moralmente buenas y que buscan ser políticamente eficaces.

Son dos las razones por las que creo que es un significativo acierto la publicación facsimilar de la revista.

Por un lado, ahora tenemos la posibilidad de consultar íntegramente los trece números publicados. De esta manera disponemos de un valioso material de consulta para comprender el crucial proceso social y político del periodo 1972-1983. Esta etapa constituye una bisagra en el desenvolvimiento de la sociedad peruana. Se cierra una época y se abre otra en el Perú contemporáneo. El régimen militar del general Velasco Alvarado erradica las bases económicas, políticas y sociales sobre las que se asentaba el poder oligárquico y se inicia una profunda reorganización del orden social que ha dado lugar al Perú de hoy. En sentido son fundamentales cuatro artículos que corresponden a tres coyunturas claves en ese periodo.

El primero de Aníbal Quijano "Imperialismo y capitalismo de estado" en el número 1 de la revista donde señala que "se puede calificar el proyecto peruano de desarrollo como el de una economía estatal-privada, con elementos neo capitalistas y tendiendo a largo plazo al predominio del sector estatal". Por esta razón, consideraba que a largo plazo se iba a consolidar el capitalismo de estado al cual el capitalismo privado estaría subordinado; pero ambos estarían articulados al neoimperialismo.

El segundo artículo fundamental fue el de Julio Cotler que se publicó en el número 2 de la revista con el título de "Bases del corporativismo en el Perú" donde analiza el diseño corporativo del Estado peruano. "El corporativismo -señala Cotler- es un esquema de organización política en el que se segmenta las clases sociales, integrando verticalmente, es decir autoritariamente, a estos segmentos en organizaciones policlasistas de carácter funcional, esto es por sectores de actividad económica y social". De esta manera el Estado velasquista buscaba articular su base económica como un capitalismo de estado y su base política como una democracia corporativa.

El tercer artículo que me gustaría resaltar lo publicó Aníbal Quijano en el número 5 de la revista - "La "segunda fase" de la "revolución peruana" y la lucha de clases"- a propósito del golpe militar que derrocó a Velasco y llevó a la presidencia al general Morales Bermúdez. El texto examina las bases de los cambios producto de una recomposición política del régimen militar y del frente capitalista y las alternativas de la lucha de clases en el país.

El cuarto artículo, creo que es imprescindible para comprender la transición del régimen militar a la democracia liberal, lo publicó Aníbal Quijano en el número 10 de la revista con el título de "Los usos de la democracia burguesa". Allí sostiene que la democracia burguesa tiene dos usos: "Primero, la contención de los movimientos de las clases dominadas" y "segundo, la ampliación y profundización y ampliación de la política pro-monopolista [ .... adueñándose del control total del aparato del Estado".

En los artículos citados, como en los diversos textos publicados en la revista, se pueden examinar análisis y reflexiones para comprender el periodo en el que se publicó la revista donde se encuentran las tendencias principales que han configurado el Perú de las últimas tres décadas.

De otro lado, creo que la importancia de la publicación facsimilar de Sociedad y Política radica en que allí podemos encontrar una perspectiva de análisis de la realidad histórico social, alternativa al de la ciencia social dominante, que puede ser muy fecunda para comprender el mundo en el que vivimos. 
Un principio fundamental de esta perspectiva es la consideración de la existencia social como una totalidad compleja. De allí que para comprender el significado del velasquismo sea necesario considerarlo en el contexto de las transformaciones que se estaban produciendo en el sistema mundial. En varios artículos se enfatiza el papel que jugó crisis mundial del capitalismo en los límites a los que llegó el régimen militar y que dio paso a la llamada "segunda fase de la revolución peruana" y posteriormente a la transición a la democracia liberal. En este sentido se articulaba el análisis de lo que ocurría en el Perú con lo estaba sucediendo en el mundo.

Este análisis implicaba, además, develar los procesos profundos que se encontraban detrás de los acontecimientos. Por eso el interés de poner en evidencia la lucha de clases -en particular las luchas de la clase obrera y del movimiento popular en el momento del velasquismo, en la coyuntura de la llamada "segunda fase" y en la transición a la democracia liberal. Asimismo se examinan los conflictos que atravesaban a las diferentes fracciones de la clase burguesa y de las capas medias.

Pero el análisis de los procesos de organización y transformación de la sociedad peruana de ese periodo no buscaba solo dar cuenta de lo que estaba ocurriendo en el país y en el mundo sino que estaba iluminado por un horizonte histórico de sentido que era el socialismo concebido como un orden social donde se ha socializado el poder y se ejerce la democracia directa de los productores.

Para alcanzar ese orden social igualitario y democrático se consideraba necesario un proceso de socialización del poder político tarea que asumió el Movimiento Revolucionario Socialista y que tuvo su concreción en la Comunidad Autogestionaria de Villa El Salvador, sobre todo en el periodo 1979 -1983. La CUAVES, como escribió Quijano "fue claramente, una democracia directa, donde los representantes, las autoridades y sus actos y decisiones en el ejercicio de estas responsabilidades quedaban sujetas al control directo de los miembros de la comunidad".

Para mí, la participación en Sociedad y Política fue una experiencia imprescindible en el aprendizaje de un pensamiento crítico utopístico. Se trataba de una perspectiva análisis que buscaba, a la vez, comprender las principales tendencias del desarrollo de la sociedad peruana de la manera más rigurosa posible; concebir un orden social democrático e igualitario como un nuevo horizonte histórico de sentido; y luchar políticamente de la manera más eficaz para alcanzarlo.

En esta época marcada por un conformismo generalizado, adentrarse en los trabajos publicados en Sociedad y Política constituye una fuente invalorable de inspiración para desarrollar una ciencia social crítica que permita comprender y dar respuesta a los acuciantes problemas del mundo en el que vivimos. 


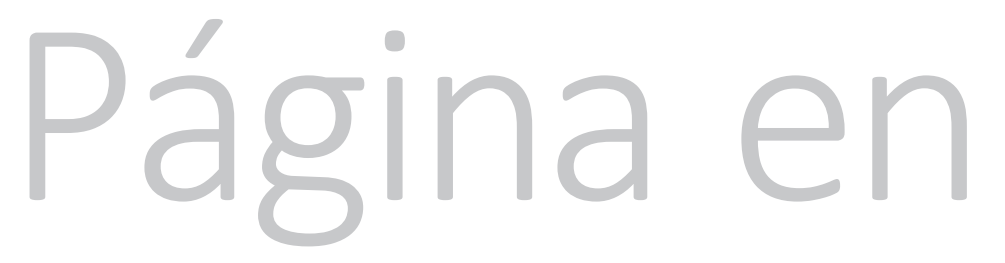

blanco 